\title{
ICME Approach to Determining Critical Pore Size of IN718 Produced by Selective Laser Melting
}

\author{
MICHAEL D. SANGID (1),,$^{1,2,4}$ PRIYA RAVI, ${ }^{1}$ \\ VEERAPPAN PRITHIVIRAJAN, ${ }^{1}$ NOLAN A. MILLER, ${ }^{2}$ \\ PETER KENESEI ${ }^{3}$ and JUN-SANG PARK ${ }^{3}$
}

\begin{abstract}
1.-School of Aeronautics and Astronautics, Purdue University, 701 W. Stadium Ave., West Lafayette, IN 47907, USA. 2.-School of Materials Engineering, Purdue University, 701 W. Stadium Ave., West Lafayette, IN 47907, USA. 3.-X-ray Science Division, Argonne National Laboratory, 9700 S. Cass Ave., Lemont, IL 60439, USA. 4.—e-mail: msangid@purdue.edu
\end{abstract}

\begin{abstract}
A degree of porosity is expected in additively manufactured (AM) materials. To aid in the qualification of AM materials, the smallest pore size that results in a debit in the fatigue performance is quantified. In the work presented herein, crystal plasticity simulations are used to identify the stress concentration around pores of various sizes, revealing that a single $20-\mu \mathrm{m}$ pore or two $10-\mu \mathrm{m}$ pores (with centers spaced $15 \mu \mathrm{m}$ apart) localize stress at the pore, as opposed to elsewhere in the microstructure. In situ microtomography and far-field high-energy x-ray diffraction microscopy were used to identify crack formation and the evolution of the grain-level micromechanical fields during cyclic loading. Eighteen cracks were observed (15 at pores, 3 at the surface) at highly stressed grains in a sample, although most did not propagate. The dominant crack was seen to originate from the free surface, which is rationalized by fracture mechanics.
\end{abstract}

\section{INTRODUCTION}

Additive manufacturing (AM) provides a transformative means to produce parts with complex geometries and streamline the product supply chain. ${ }^{1}$ Yet, before these parts produced via AM can be used in structural applications, their durability and structural integrity must be assessed. ${ }^{2}$ The qualification of aerospace materials produced by selective laser melting (SLM) is investigated herein. Due to inherent porosity present in the powder feedstock, rapid solidification process, non-optimized process parameters, or laser path routes, porosity is present in materials produced by SLM. ${ }^{3-12}$ Researchers have tailored the SLM process parameters to reduce porosity, ${ }^{3-11}$ yet some degree of porosity is still present, especially since pores can regrow after hot isostatic pressing (HIPing), ${ }^{12}$ and porosity is more prevalent in the regions between the outer contour and inner hatch. ${ }^{13}$ It is well documented that porosity can result in fatigue crack initiation. ${ }^{5,10,14-20}$ In the work presented herein, the critical size of the pores that are prone to fatigue cracks is investigated and quantified for Inconel 718 material produced by SLM.

The role of porosity in the fatigue properties has been assessed in traditional cast ${ }^{21}$ and powder metallurgy ${ }^{22}$ materials, which is based on specimen-level testing and fractography investigation post mortem. The sizes of pores that initiate fatigue cracks have been applied in a Murakami-type analysis, ${ }^{23}$ where the defect strength is taken as the remote stress multiplied by a factor of the square root of the projected area of the pore onto the principal stress axis, ${ }^{24,25}$ or a Kitagawa-Takahashi method, ${ }^{26}$ which relates the fatigue crack growth threshold concept to the high-cycle fatigue (HCF) endurance limit. ${ }^{25}$ These methods have been applied to AM materials, ${ }^{15}$ although these approaches do not capture the complex interactions of the local microstructure surrounding the pore. Recent reports on qualification of AM materials recommend more detailed investigations into the role of AM porosity defects in fatigue properties, along with the establishment of nondestructive 
techniques (NDTs) to detect these defects in AM parts (although it still remains to be determined whether NDT is required on the first part produced, witness coupons for each AM batch, each critical part, etc.). ${ }^{27,28}$

An integrated computational materials engineering (ICME) approach has been touted to reduce the time and cost necessary to accelerate the adoption of new materials to market, ${ }^{29,30}$ and offers tremendous benefits to the AM community. ${ }^{31}$ A combined modeling and experimental approach is taken herein. First, crystal plasticity simulations ${ }^{32}$ are used to identify the stress state around a pore, in the regime in which the pore size is similar to the microstructural features. ${ }^{12,33,34}$ These grain-level stress fields are used to identify the critical pore size, in which the stress concentrations around a pore are greater than those around other microstructural features (especially grain boundaries). Next, a pair of synchrotron-based $\mathrm{x}$-ray characterization techniques are used during in situ loading ${ }^{35}$ to produce a data-rich means to identify the role of pores in the fatigue behavior, and to inform and validate the model's predictions. Specifically, microcomputed tomography $(\mu \mathrm{CT})$ identifies the location, size, and morphology of the pores, along with the presence and evolution of cracks during testing. ${ }^{36-39}$ Far-field high-energy x-ray diffraction microscopy (ff-HEDM) quantifies the lattice strain in each grain within the illuminated region. ${ }^{40-42}$

\section{MATERIALS, PROCESSING, AND FATIGUE LOADING}

Inconel 718 (IN718) was built into 50.8-mm cubes via SLM using an EOSINT M280 system at Penn State University with build parameters as indicated, based on the EOS IN718 Performance 101 settings. ${ }^{13}$ The samples underwent stress relief ( $1065^{\circ} \mathrm{C}$ for $1.5 \mathrm{~h}$ in Ar followed by 2-bar Ar cooling) and three-step heat treatment in Ar, consisting of vacuum homogenizing $\left(1177^{\circ} \mathrm{C}\right.$ for $1 \mathrm{~h}$ followed by 2 bar Ar cooling at $38^{\circ} \mathrm{C} / \mathrm{h}$ to below $538^{\circ} \mathrm{C}$ ), solution treatment $\left(982^{\circ} \mathrm{C}\right.$ for $1 \mathrm{~h}$ followed by gas fan cooling with $\mathrm{Ar}$ to below $\left.149^{\circ} \mathrm{C}\right)$, and aging $\left(718^{\circ} \mathrm{C}\right.$ for $8 \mathrm{~h}$, then furnace cooling to $621^{\circ} \mathrm{C}$ and holding for $18 \mathrm{~h}$, before being gas fan cooled with $\mathrm{Ar}$ to below $149^{\circ} \mathrm{C}$ ). These specimens were not subjected to HIPing due to a twofold rationale. First, it is a strategic goal to reduce the reliance of HIPing in the AM supply chain; and second, this study focuses on the role of porosity, hence it is prudent to have a representative distribution of pores in each sample. Detailed characterization of the grain, precipitate, and pore structures was presented in Refs. 13 and 43 for material built during the same SLM batch as the present study. Specimens were extracted from the blocks via wire electrodischarge machining to produce a series of samples, as shown in Fig. 1a, which were designed to localize failure within a small region at the center of the gauge section, to minimize the volume of material that needed to be characterized. The longitudinal axis of each sample was aligned with the build direction. Afterwards, the gauge section of each specimen was manually polished.

Samples were tested under HCF conditions, in which maximum applied stress was roughly $70 \%$ of the yield stress of the material $\left(1126 \mathrm{MPa}^{13}\right)$. The material was cyclically loaded between $800 \mathrm{MPa}$ and $10 \mathrm{MPa}(R \approx 0.01)$ at a frequency of $20 \mathrm{~Hz}$. A preliminary set of eight specimens were tested under these HCF conditions, and these sets of samples failed between 37,461 cycles and 70,161 cycles, following a log-normal distribution with an average of 53,867 cycles to failure. The fracture surface of each specimen was characterized via a Nova NanoSEM at $20 \mathrm{kV}$ with spot size of 4.0 and working distance of $5.7 \mathrm{~mm}$. The results showed that five samples failed at a free surface, while three samples failed via a crystallographic facet. Pores were detectable on the facet surfaces, as this represents a potential weak path for the crack to form. ${ }^{44,45}$ Fig. 1 shows one such surface, in which the sample failed via a crystallographic facet, yet considerable porosity was shown on the facet surface. From this, it could be said that this failure is largely crystallographic in nature (and not necessarily driven by porosity), yet the pores aided in the crack formation. The porosity within these facets was quantified via ImageJ. ${ }^{46}$ The facet size, shown in Fig. 1b, was measured to be $9500 \mu \mathrm{m}^{2}$, with a size distribution of the pores on the facet surface ranging from $0.3 \mu \mathrm{m}$ to $14 \mu \mathrm{m}$, and an area fraction of $2.7 \%$. The area fraction of pores on the fracture surface is considerably higher than the volume fraction of porosity in this material $\left(0.045 \%^{13}\right)$. For completeness, the facet sizes from the other two failed surfaces were $26,600 \mu \mathrm{m}^{2}$ and $12,600 \mu \mathrm{m}^{2}$, with an area fraction of $\sim 1 \%$. These preliminary fatigue studies illuminate the importance of relatively small pores for the crack initiation process, although conducting a large-scale test matrix on individual specimens is time-consuming and costly. Hence, in the present paper, an ICME approach is used to explore the role of small pores on fatigue crack initiation through a combination of microstructure-sensitive crystal plasticity modeling and in situ experiments.

\section{METHODS}

\section{High-Energy X-ray Characterization}

The high-energy x-ray characterization experiments were performed at beamline 1-ID-E of the Advanced Photon Source (APS), Argonne National Laboratory. The experiments were conducted in transmission geometry using x-rays with energy of $71.676 \mathrm{keV}(\lambda=0.017297 \mathrm{~nm})$. The region of interest (ROI) was a 3 -mm-tall region centered around the middle of the gauge section. A combination of three-dimensional (3D) nondestructive characterization techniques, $\mu \mathrm{CT}$, and ff-HEDM were used; 

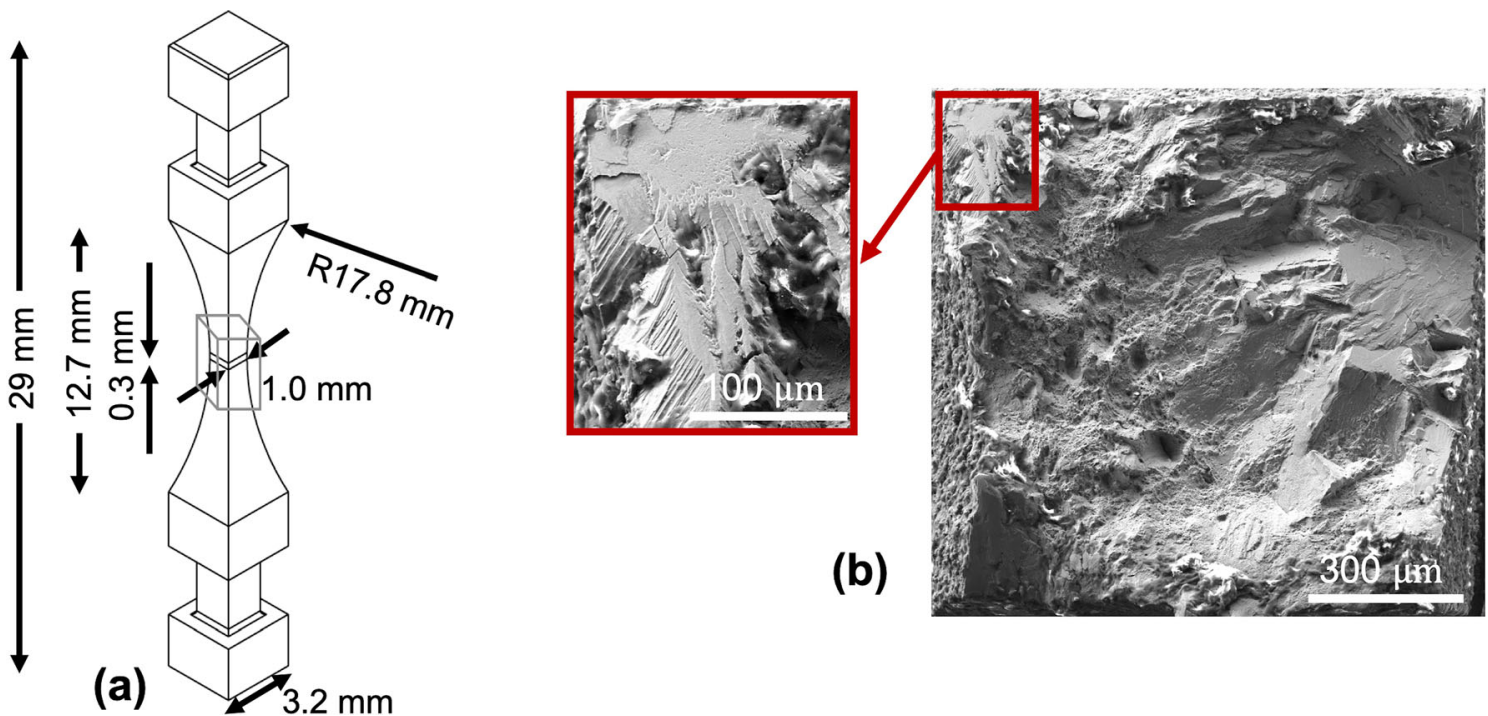

Fig. 1. (a) Sample geometry. (b) Fracture surface after HCF testing, in which the specimen failed via a crystallographic facet. The porosity area fraction was $2.7 \%$ within the facet (as shown in the inset), which is considerably higher than the volume fraction of porosity in the overall sample, $0.045 \%$

the beam and detector settings of each one are described in the paragraphs that follow. The specimen had a fiducial Au cube attached to help facilitate feature tracking. ${ }^{47}$ The specimen was subjected to fatigue loading using a rotational and axial-torsional motion system (RAMS3), which is able to simultaneously apply axial load on the specimen and rotate the specimen without obstructing the path of the incoming or outgoing x-ray beam. ${ }^{48}$ The loading conditions were the same as previously reported (800 $\mathrm{MPa}$ to $10 \mathrm{MPa}$ ), except the frequency was set to $\leq 1 \mathrm{~Hz}$. The sample was interrupted at 20 cycles, 15,000 cycles, 43,000 cycles, 51,000 cycles, 55,000 cycles, 59,000 cycles, and 71,000 cycles, and held in displacement control under maximum load to conduct the $\mu \mathrm{CT}$ and ffHEDM characterization, while at 200 cycles and 2000 cycles only ff-HEDM was conducted.

For ff-HEDM, a box beam with height of $125 \mu \mathrm{m}$ was used to illuminate the specimen, diffraction patterns were collected every $0.25^{\circ}$ as the specimen was rotated $360^{\circ}$ about its loading axis. The specimen was then translated vertically by $125 \mu \mathrm{m}$, and the scan was repeated. A total of 24 box scans were used to probe the entire ROI. An area detector with an array of $2048 \times 2048$ pixels with a pitch of $200 \mu \mathrm{m}$ was used to capture the diffraction spots corresponding to grains that had satisfied the Bragg condition. The detector was located $880 \mathrm{~mm}$ from the specimen, which enabled acquisition of eight complete diffraction rings. Lead tape was used to attenuate the first two rings, to minimize their diffracted intensity on the detector. Given the large grain size distribution in this sample $(50 \mu \mathrm{m}$ average, including twins), ${ }^{13}$ a $125-\mu \mathrm{m}$ box enabled the identification of low-intensity spots corresponding to smaller grains with minimal intensity saturation on the detector for spots, corresponding to larger grains. The experimental setup was calibrated using ceria $\left(\mathrm{CeO}_{2}\right)$ powder and gold samples. For the analysis, the first four Debye-Scherrer rings-belonging to the $\{111\},\{020\},\{220\},\{131\}$ crystallographic planes-were used to reconstruct the ff-HEDM data using the MIDAS analysis package. ${ }^{49,50}$ The reference lattice parameter of this material is $0.3592 \mathrm{~nm}$, which was determined by analyzing the ff-HEDM data acquired at the initial state. From ff-HEDM, 2056 unique grains were identified in the ROI, using a completeness value of $0.7 .^{51}$

Phase-contrast $\mu \mathrm{CT}$ was used to characterize and quantify the void and crack information within the specimen. Three 1.2-mm-tall boxes were used to characterize the ROI, with a $100 \mu \mathrm{m}$ overlap between each consecutive box. The tomography detector was placed at a distance of $\sim 90 \mathrm{~mm}$ from the specimen, and its pixel size was $1.17 \mu \mathrm{m}$. The sample was rotated by $360^{\circ}$ about its loading axis, and radiographs were taken at every $0.1^{\circ}$. The tomography data were reconstructed via a MATLAB-based code developed at the APS. ${ }^{52}$ Further postprocessing was done using a combination of MATLAB, ImageJ, and Avizo, and visualization of the reconstructed $3 \mathrm{D}$ volume was done using Avizo. ${ }^{53}$ The three reconstructed $\mu \mathrm{CT}$ volumes were consolidated, and a thresholded tomography mask was created to preserve the information of the pores, potential cracks, and specimen perimeter for the complete ROI, as shown in Fig. 2a. The size of each pore was measured, based on a spherical equivalent diameter, which is shown in Fig. $2 \mathrm{~b}$. The average pore size was $5.3 \mu \mathrm{m}$, with the largest pore in the ROI being $26.3 \mu \mathrm{m}$. The sphericity measures the deviation of the pore morphology from 

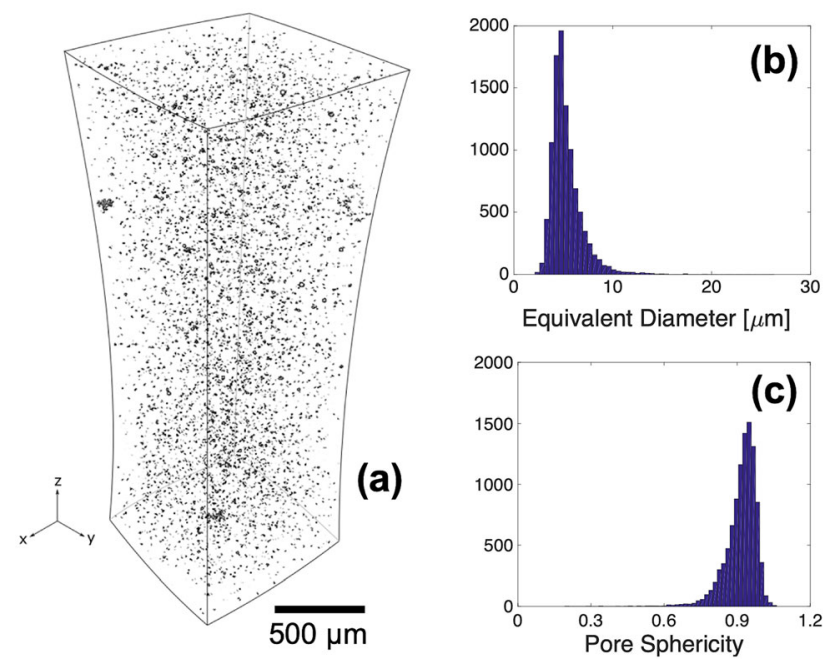

Fig. 2. (a) Porosity as measured via $\mu \mathrm{CT}$ characterization, in 3-mm ROI (shown in gray box of Fig. 1a), (b) volume-weighted equivalent pore diameter, and (c) morphology of the pores, as measured via the sphericity metric.

a sphere (with a value of 1 representing a perfect sphere). The sphericity is shown in Fig. 2c with the average sphericity measuring 0.92 . Since most of the pores were nearly spherical, presumably resulting from trapped gas during processing or porosity present in the initial powders, subsequent analysis focused on spherical pores and did not investigate the role of pore shape.

The reconstructed $\mu \mathrm{CT}$ and ff-HEDM results for the complete ROI were consolidated to amalgamate the two datasets. The simplified 3D microstructure features were recreated by Laguerre tessellation from the grain centroids using DREAM.3D, ${ }^{54}$ and the position of the voids were superimposed on the microstructure. The ff-HEDM reconstructions provided information regarding the location of the grain centroid, orientation, and grain-averaged elastic strain tensor, $\epsilon_{i j}^{\mathrm{e}}$, for each grain in the ROI. The grain average stress $\left(\sigma_{k l}\right)$ could be determined through Hooke's law:

$$
\sigma_{k l}=C_{i j k l} \epsilon_{i j}^{\mathrm{e}},
$$

where the constants for the single-crystal elastic tensor $C_{i j k l}$ in Voigt's notation with cubic symmetry are $C_{11}=225.7 \mathrm{GPa}, C_{12}=151.2 \mathrm{GPa}$, and $C_{44}=112.3 \mathrm{GPa}^{34}$

\section{Computational Modeling}

Based on the grain-scale microstructural characterization [grain size distribution, aspect ratio (equiaxed in this case), orientation distribution (random), and fraction of twin boundaries] as well as strength characteristics (yield stress, hardening response, and reverse yield upon unloading), a 3D synthetic microstructure instantiation of size $300 \mu \mathrm{m} \times 300 \mu \mathrm{m} \times 300 \mu \mathrm{m}$ comprising 190 grains was created. For further details of the microstructure generation, the reader is referred to Ref. 34. The virtual microstructure was subjected to a crystal plasticity simulation, in which the kinematics of slip are captured using the multiplicative decomposition ${ }^{55}$ of the total deformation gradient, $\boldsymbol{F}$, as

$$
\boldsymbol{F}=\boldsymbol{F}_{\mathbf{e}} \boldsymbol{F}_{\mathbf{p}}
$$

where $\boldsymbol{F}_{\mathbf{e}}$ and $\boldsymbol{F}_{\mathbf{p}}$ represent the elastic and plastic deformation gradient, respectively. The plastic velocity gradient, $\boldsymbol{L}_{\mathbf{p}}$, is related to the shearing rate, $\dot{\gamma}^{\alpha}$, on slip system $\alpha$ as

$$
\boldsymbol{L}_{\mathbf{p}}=\sum_{\alpha=1}^{12} \dot{\gamma}^{\alpha} \boldsymbol{s}^{\alpha} \otimes \boldsymbol{n}^{\alpha}
$$

where $\boldsymbol{s}^{\alpha}$ is the slip direction and $\boldsymbol{n}^{\alpha}$ is the slip plane normal. A power-law flow rule is used to relate the shear strain rates, $\dot{\gamma}^{\alpha}$, to the resolved shear stress, $\tau^{\alpha}, 56$

$$
\dot{\gamma}^{\alpha}=\dot{\gamma}_{0}\left|\frac{\tau^{\alpha}-\chi^{\alpha}}{g^{\alpha}}\right|^{n} \operatorname{sgn}\left(\tau^{\alpha}-\chi^{\alpha}\right),
$$

where $\dot{\gamma}_{0}$ is the reference shear strain rate; $\mathrm{g}^{\alpha}$ and $\chi^{\alpha}$ are the reference stress and back stress, respectively; $n$ is the inverse strain-rate sensitivity exponent. The evolution laws for the reference and the back stresses are modeled using Armstrong-Frederick functional forms: ${ }^{57}$

$$
\begin{gathered}
\dot{g}^{\alpha}=H \sum_{\beta=1}^{12} q^{\alpha \beta}\left|\dot{\gamma}^{\beta}\right|-H_{\mathrm{d}} g^{\alpha} \sum_{\beta=1}^{12}\left|\dot{\gamma}^{\beta}\right|, \\
\dot{\chi}^{\alpha}=A \dot{\gamma}^{\alpha}-A_{\mathrm{d}} \chi^{\alpha}\left|\dot{\gamma}^{\alpha}\right|,
\end{gathered}
$$

where $H$ and $H_{\mathrm{d}} / A$ and $A_{\mathrm{d}}$ are the direct hardening and dynamic recovery coefficients, respectively, for the reference stress/back stress, respectively, $q$ is the hardening matrix, and superscripts $\alpha$ and $\beta$ represent the associated slip systems. The crystal plasticity parameters were calibrated against stress-strain hysteresis loops from macroscale specimens using a genetic algorithm. A full uncertainty quantification analysis was performed on each parameter; the results are reported in Ref. 58.

To match the experiment (in force control), the simulations are loaded to $800 \mathrm{MPa}$, along the $z$-axis with mesh details and boundary conditions reported in Ref. 34. Seven additional identical simulations were instantiated, except for a pore (of varying size) which was placed at the same location representing a node that was common to four different grains. Three models were instantiated with a single spherical pore of size $10 \mu \mathrm{m}, 20 \mu \mathrm{m}$, and $40 \mu \mathrm{m}$. The remaining four models were instantiated with two pores (of the same size) spaced at a distance to quantify stress concentration due to interaction effects. Within the two-pore microstructure models, three models had two $10-\mu \mathrm{m}$-sized pores with their centers spaced at distances of $15 \mu \mathrm{m}$ (or tip-to-tip distance of $5 \mu \mathrm{m}$ ), $19 \mu \mathrm{m}$, and $22 \mu \mathrm{m}$ apart, respectively, while the fourth model had 8- $\mu \mathrm{m}$-sized pores 
and a center separation distance of $14 \mu \mathrm{m}$ apart. The choice of the center separation distances (namely $19 \mu \mathrm{m}$ and $22 \mu \mathrm{m}$ ) was made based on the $\mu \mathrm{CT}$ data $^{34}$ (Table I), while for the other two models, the distances were set on the basis of the simulation results from the single-pore models to simulate the worst-case scenario. Transparent view of five of the microstructure instantiations are shown in the first row of Fig. 3 to indicate the pores, and their grains are colored based on their orientation relative to the inverse pole figure (IPF) triangle with respect to the $\mathrm{z}$ (loading) direction.

\section{Critical Pore Size Determination via Crystal Plasticity}

Crystal plasticity simulations were performed on each of the eight microstructures (as previously described), and the resulting visualizations for the selected relevant cases are shown in the columns of Fig. 3. The normal stress component aligned with the loading axis for each simulation is shown in the second row of Fig. 3. A slice perpendicular to the loading direction, through the pore centroids, is taken for each microstructure, and the results are shown in the third row of Fig. 3. As expected, significant concentration of stress is observed around the pores. The concentration of stress near the pore is more distinct for larger pore sizes. In the fourth row of Fig. 3, the grain-averaged stress in the loading direction is shown for the two-dimensional (2D) slice containing the pore, as this metric is directly comparable to the ff-HEDM results that will be introduced in the next section.
For each simulation, the micromechanical fields are averaged over multiple elements; in this case, the stress in the loading direction is averaged over a domain containing $2 \times 2 \times 2$ elements, as determined based on sensitivity analysis. ${ }^{34}$ The radial distribution function plots in Fig. 4 were calculated centered at the pores, for which the maximum value of stress was obtained from each spherical annulus. From these plots, the highest stress concentration can be observed near the pore for the case of a $40-\mu \mathrm{m}$ pore, $20-\mu \mathrm{m}$ pore, or two $10-\mu \mathrm{m}$ pores separated by a distance of $15 \mu \mathrm{m}$. Meanwhile, for the other five microstructures, higher stress concentration was observed in other locations relative to the microstructure. From this, we conclude that a single pore of $10 \mu \mathrm{m}$ in size will not be detrimental to the fatigue behavior of the material, as another location within the microstructure will be more likely to initiate a crack. Moreover, a single pore larger than $20 \mu \mathrm{m}$ in size, or a cluster of pores (in this case, 10$\mu \mathrm{m}$-sized pores, spaced $15 \mu \mathrm{m}$ apart, were evaluated) will create a stress concentration that is higher in value compared with the other microstructural features, and thus are denoted as the critical pore size that will affect the fatigue behavior. In a more detailed study, a series of analyses were conducted for low-cycle fatigue conditions (1\% applied strain), which showed similar results. ${ }^{34}$

\section{In Situ High-Energy X-ray Experiments}

To validate the critical pore size determined via crystal plasticity in the preceding section, fractography could be conducted on a series of specimens

Table I. Crack and pore statistics for the ROI subjected to in situ $\mu$ CT characterization during cyclic loading

\begin{tabular}{|c|c|c|c|c|c|c|c|}
\hline $\begin{array}{l}\text { Crack } \\
\text { ID }\end{array}$ & $\begin{array}{l}\text { Site of } \\
\text { crack }\end{array}$ & $\begin{array}{c}\text { Equivalent } \\
\text { pore } \\
\text { diameter } \\
(\mu \mathrm{m})\end{array}$ & $\begin{array}{c}\text { Cycle at } \\
\text { observation } \\
\text { of crack }\end{array}$ & $\begin{array}{c}\text { Initial } \\
\text { crack } \\
\text { length } \\
(\mu \mathrm{m})\end{array}$ & $\begin{array}{c}\text { Crack length } \\
\text { at } 71 \mathrm{k} \text { cycles } \\
(\mu \mathrm{m})\end{array}$ & $\begin{array}{l}\text { Distance to } \\
\text { closest pore } \\
(\mu \mathrm{m})\end{array}$ & $\begin{array}{l}\text { Distance to } \\
\text { free surface } \\
(\mu \mathrm{m})\end{array}$ \\
\hline MC1 & Pore & 10.6 & 1 & 13.5 & 15.5 & 30.0 & 244.6 \\
\hline MC2 & Pore & 9.4 & 1 & 11.1 & 11.1 & 16.5 & 252.6 \\
\hline MC3 & Pore & 11.5 & 1 & 10.4 & 10.4 & 16.9 & 339.2 \\
\hline MC4 & $\begin{array}{l}\text { Connected } \\
\text { pores }\end{array}$ & 6.6 & 1 & 8.3 & 8.3 & 14.4 & 273.1 \\
\hline MC5 & Pore & 9.7 & 1 & 13.4 & 13.4 & 18.2 & 47.0 \\
\hline MC6 & Pore & 10.6 & 1 & 9.5 & 15.2 & 11.5 & 116.3 \\
\hline MC7 & Pore & 7.7 & 1 & 8.8 & 8.8 & 21.5 & 117.5 \\
\hline MC8 & Pore & 7.6 & 1 & 11.9 & 11.9 & 20.4 & 36.6 \\
\hline MC9 & Pore & 12.6 & 1 & 9.9 & 9.9 & 29.1 & 296.3 \\
\hline MC10 & Pore & 6.6 & 1 & 6.2 & 9.0 & 32.8 & 65.8 \\
\hline IC1 & Pore & 12.5 & 15,000 & 14.4 & 17.0 & 21.2 & 288.5 \\
\hline IC2 & $\begin{array}{l}\text { Connected } \\
\text { pores }\end{array}$ & 8.8 & 43,000 & 13.4 & 13.4 & 25.4 & 155.8 \\
\hline IC3 & Pore & 19.7 & 15,000 & 14.5 & 16.7 & 19.9 & 199.5 \\
\hline IC4 & Pore & 9.4 & 43,000 & 7.6 & 7.6 & 46.2 & 49.9 \\
\hline IC5 & Pore & 13.3 & 23,000 & 7.7 & 9.4 & 66.5 & 331.9 \\
\hline $\mathrm{S} 1$ & Surface & - & 15,000 & 30.2 & 85.0 & 81.0 & 0 \\
\hline $\mathrm{S} 2$ & Surface & - & 15,000 & 26.3 & 286.4 & 219.8 & 0 \\
\hline S3 & Surface & - & 15,000 & 29.6 & 110.5 & 93.6 & 0 \\
\hline
\end{tabular}




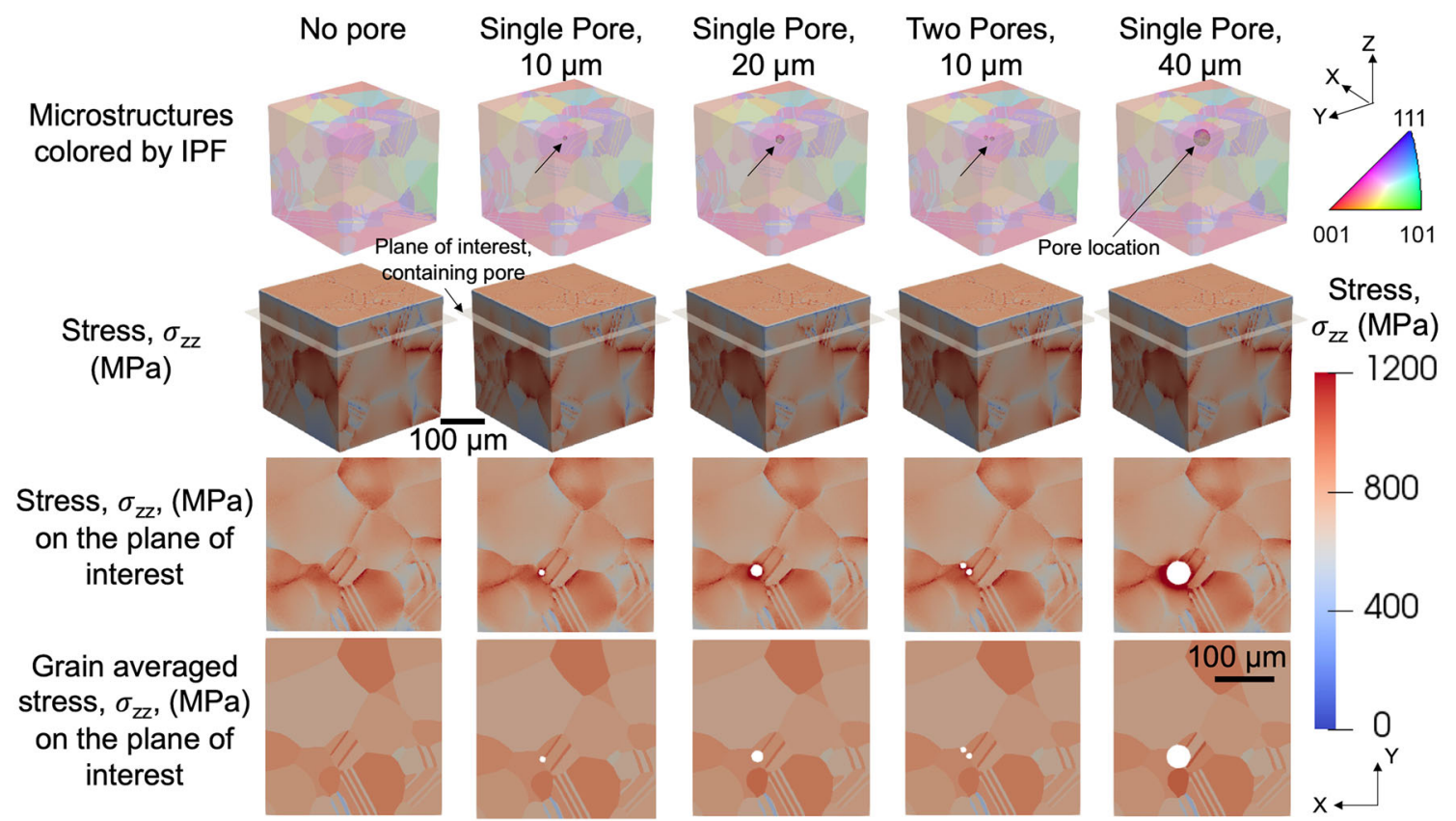

Fig. 3. Crystal plasticity simulations of five of the same microstructures (first row) and resulting stress fields, $\sigma_{z z}$, for each simulation (second through fourth rows): without the presence of pores, with a single pore of $10 \mu \mathrm{m}$, with a single pore of $20 \mu \mathrm{m}$, with two pores of $10 \mu \mathrm{m}$ (with centers $15 \mu \mathrm{m}$ apart), and with a single pore of $40 \mu \mathrm{m}$ (each shown in one of the columns).

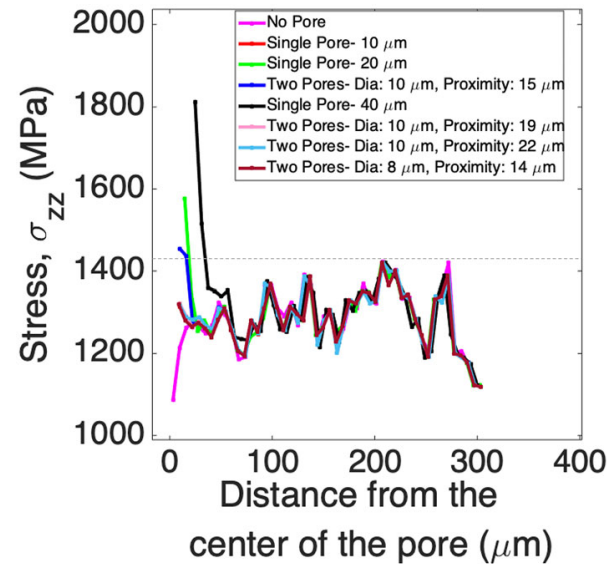

Fig. 4. Radial distribution function of the stress with respect to the distance from the center of the pore for each simulation in Fig. 3, as well as two $10-\mu \mathrm{m}$ pores with centers $19 \mu \mathrm{m}$ and $22 \mu \mathrm{m}$ apart and two $8-\mu \mathrm{m}$ pores with centers $14 \mu \mathrm{m}$ apart.

(as shown in Fig. 1b), although this procedure would provide one data point (for pore-mediated failure) per specimen and thus would be time and cost-intensive. Another path forward is the use of in situ experiments, which produces a data-rich means to validate computational models and aligns with the philosophy of ICME. The sample subjected to high-energy x-ray characterization during in situ fatigue loading was monitored for crack formation. In the work presented herein, 18 cracks were observed in the ROI. The cracks were identified based on the grayscale intensity maps, in which intensity line traces across the crack features were used to confirm the existence of cracks. This methodology is based on best practices for determining cracks based on $\mu \mathrm{CT}$ analysis. ${ }^{59-61}$ These line traces were then compared across load steps to identify the evolution of the cracks. The crack statistics are reported in Table I.

The cracks were categorized as those present during the first tomography scan originating from pores (referred to as manufacturing cracks), cracks initiating from pores, and cracks initiating from the free surface. Each crack was monitored to see if they grew (within a two-pixel resolution, $\sim 3 \mu \mathrm{m}$ ) between the first observed instance and the final $\mu \mathrm{CT}$ scan at 71,000 cycles. As such, each crack was categorized as either propagating or nonpropagating. These classes of cracks were plotted against the equivalent pore diameter (treating each pore as a sphere), as shown in Fig. 5a. The manufacturing pores experiencing cracking were $<13 \mu \mathrm{m}$, and most of the cracks were not seen to propagate during cyclic loading. Further, for each crack, the distance from the free surface and distance to the nearest-neighboring pore were also graphed. Cracks which originated from smaller pores were typically closer to the free surface, while no trends were observed between the pore size which initiated cracks and the distance to the nearest-neighboring pore. By comparing the overall pore sizes in the ROI (Fig. 2b) with the sizes of pores in which a crack initiated, statistically the larger pores were more prone to initiate a crack, although the largest pore did not experience crack formation, which means that pore size alone is not sufficient to predict crack formation. In Fig. 5b, the crack size is plotted against the first observation of the crack. Note that 

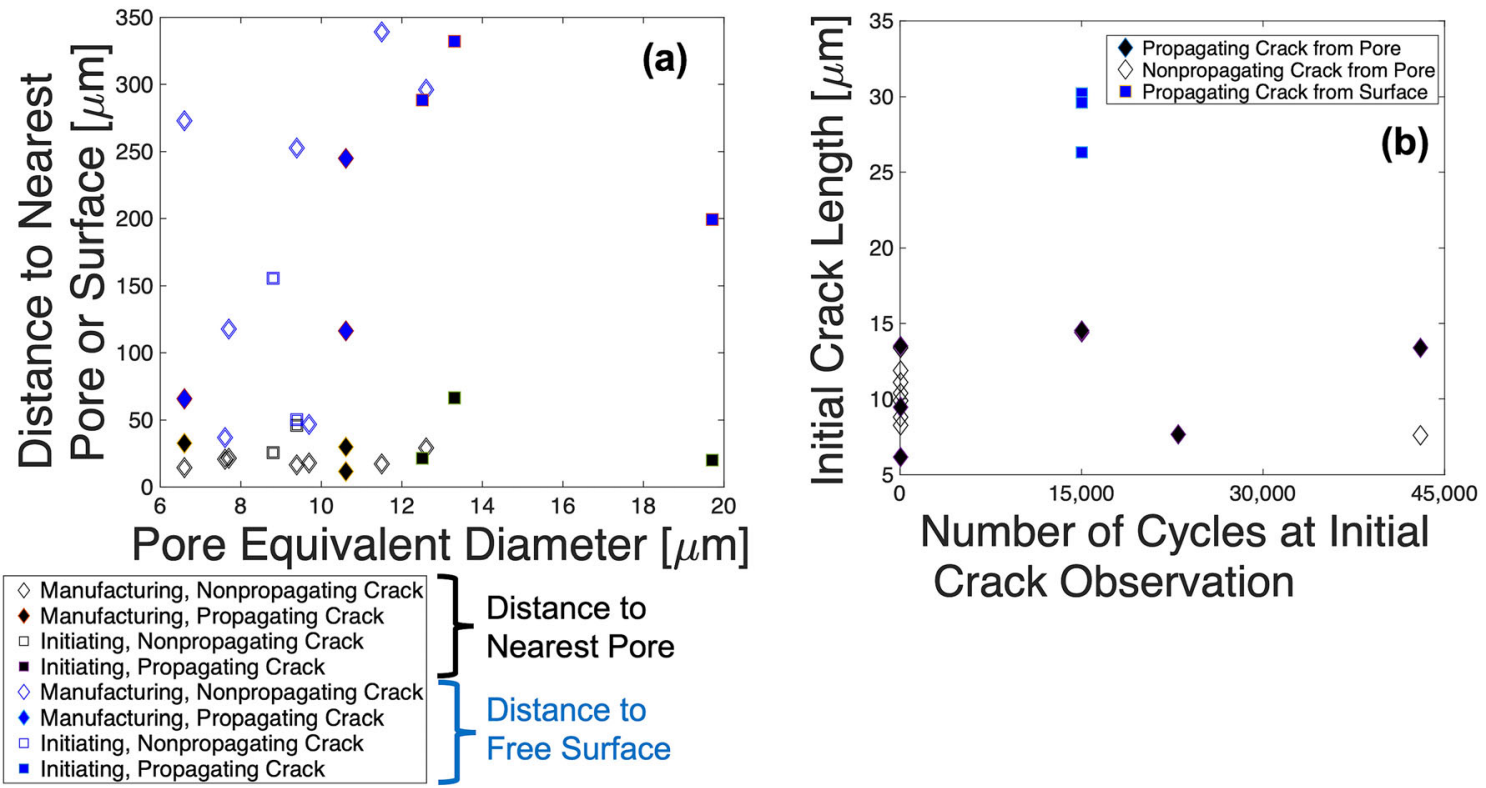

Fig. 5. (a) Pore size (equivalent diameter), in which cracks were observed, based on distance to the free surface (blue) or distance to the nearest pore (black). The cracks are categorized based on observation during the first $\mu \mathrm{CT}$ scan (termed manufacturing) or initiating during cyclic loading, as well as whether the crack was observed to propagate or not. (b) The initial crack length during the first observation of the crack (for cracks originating from pores or the free surface).

$\mu \mathrm{CT}$ scans were taken at discrete nonregular intervals; hence the initial crack length may include some small amount of crack propagation. From this analysis, the cracks initiating from the free surface were significantly larger than the cracks initiating at the pore. A material point at the free surface has additional degrees of freedom, which is associated with an increased ease of accommodating deformation provided by the traction-free surface, compared with a material point in the bulk which has additional constraints.

To investigate the role of the surrounding microstructure, a representative crack was chosen (IC2 in Table I). As seen in the upper-left insets of Fig. 6, a crack developed at the left pore after 43,000 cycles. The ff-HEDM analysis provided grain-averaged lattice strains, which can be used to quantify the stress state in each grain from Eq. 1. The stress in the loading direction for each grain in the ROI is graphed as a cumulative distribution function (CDF) in the upper-right insets of Fig. 6; and the grain level stress (in the loading direction) is shown spatially around the pores in Figs. 6a, b, and c at 20, 15,000 , and 43,000 cycles; respectively. Note that the morphology of the grains is not known from ffHEDM, and a simple tessellation is shown. Further, smaller grains may be present in the microstructure and were not indexed during the ff-HEDM reconstruction. Nonetheless, it can be seen that the stress state in the grain near the pore that experienced cracking is significantly high compared with the distribution of stress states in the ROI (indicated by an arrow in the CDF plot). The ff-HEDM metric provides a grain-averaged value of stress and does not account for stress gradients near the pore, hence this is an incomplete metric to identify and understand the micromechanical fields around a pore. As shown in the bottom row of Fig. 3, by taking a grainaverage value of the stress around a pore, most of the stress concentration around the pore is diluted. Hence, the ff-HEDM results are not expected to produce a one-to-one comparison between stress concentration around a pore and the likelihood of crack formation.

The dominant crack in the ROI originated from the surface (S2 in Table I), in which the grainaveraged stresses around this surface crack are shown in Figs. $6 \mathrm{~d}$ and e prior to and after crack initiation (at cycles 20 and 15,000), respectively. The crack morphology for S2 is shown in Fig. 7, after 71,000 cycles. This crack displays a tortuous nature, indicative of short crack growth, as the crack is heavily influenced by the local microstructure, and the crack displays mode II behavior. Moreover, branching of the crack towards the upper pore is observed in Fig. 7c, as the pores influence the local stress field and therefore the short crack growth behavior. As the crack advances, there is a mode I restoring mechanism, in which the crack starts to grow perpendicular to the applied loading. ${ }^{62}$ Based on a simple fracture mechanics perspective, the geometric correction factor applied to the stress intensity factor for crack growth is $12 \%$ higher for a surface-connected crack, as opposed to a crack confined within the bulk of the material. ${ }^{63}$ Hence, for similar grain-level stress states (as shown in Fig. 6), the surface connected crack will propagate at a faster rate than a crack that originates from a pore in the bulk of the material. Moreover, in fracture mechanics, a crack in the bulk 

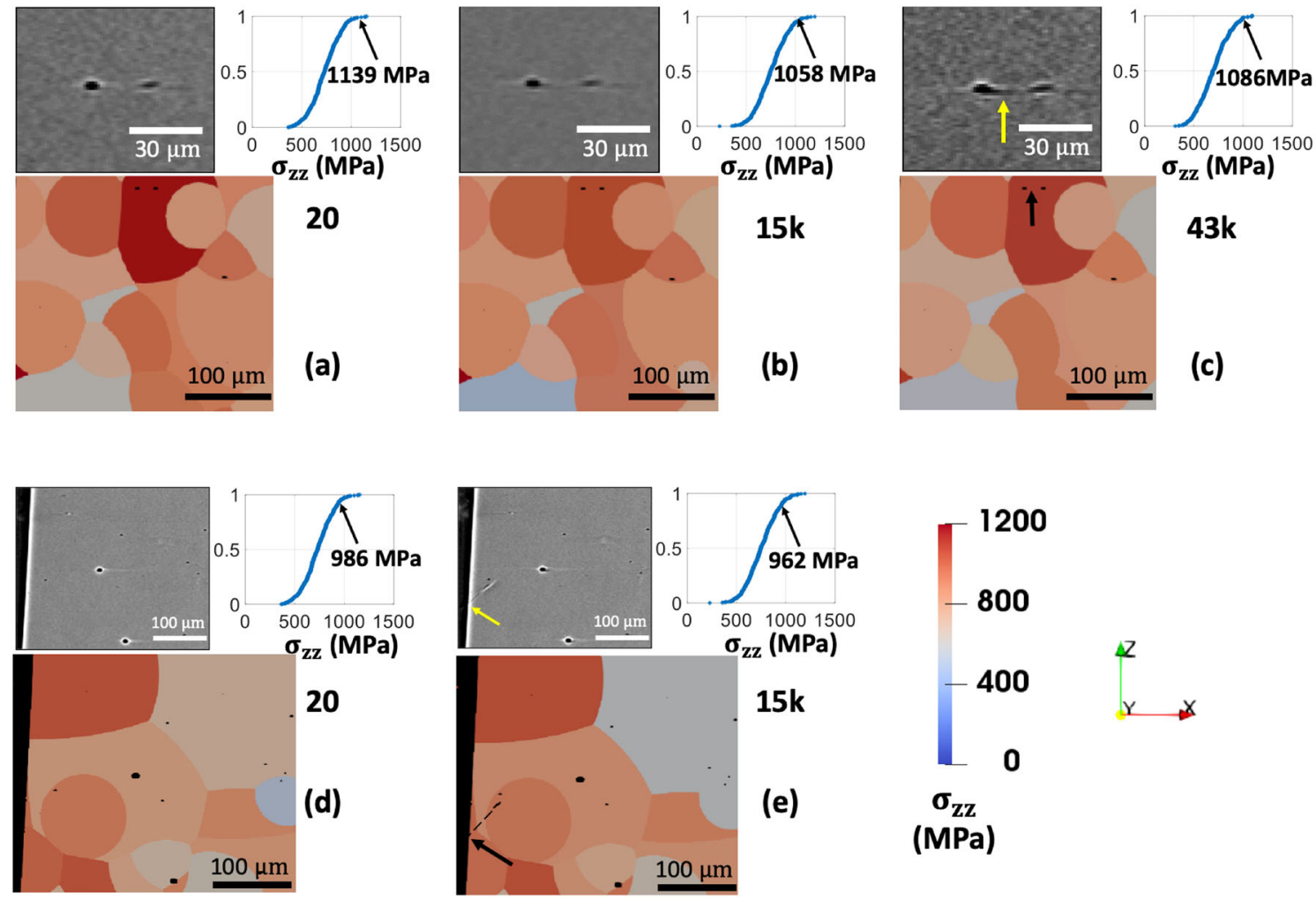

Fig. 6. (Top row) A crack initiating from a pore (adjacent to another pore) during cyclic evolution at (a) 20 , (b) 15,000 (denoted as $15 \mathrm{k}$ ), and (c) 43,000 (denoted as $43 \mathrm{k}$ ) cycles. (Bottom row) A crack initiating from the free surface during cyclic loading at (d) 20 and (e) 15,000 cycles. For each set of images-(top left) the grayscale intensity map from the $\mu \mathrm{CT}$ scan is shown, with the crack initiation marked with a yellow arrow; (top right) the cumulative distribution plot of the stresses in the ROI, with grain-averaged stress in the vicinity of crack initiation indicated with an arrow; and (bottom) ff-HEDM map of stresses near the site of crack initiation (Color figure online).
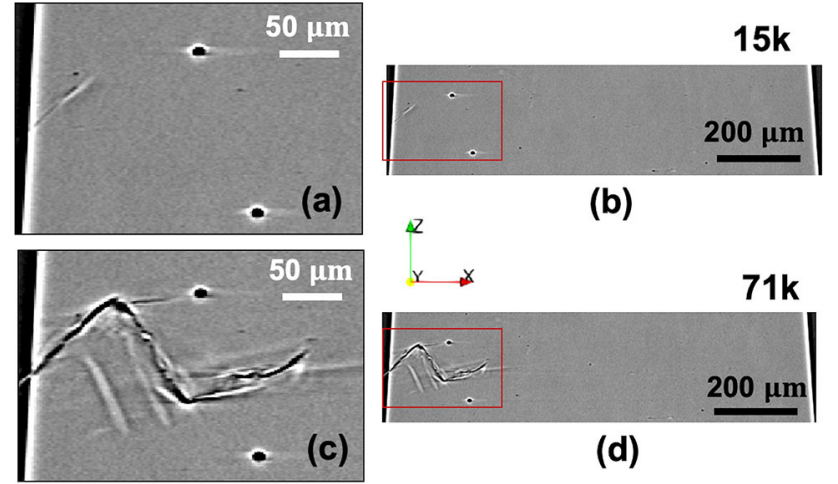

(d)

Fig. 7. For the dominant crack in the ROI, crack growth is shown after (a, b) 15,000 cycles and (c, d) 71,000 cycles. (b, d) Display of the entire width of the specimen with red box indicating the zoomedin regions shown in (a, c) (Color figure online).

of the material is denoted with a length of $2 a$, whereas a surface crack is denoted with a length of $a$; which further increases the stress intensity factor for a surface crack, as opposed to a crack in the bulk of the material. Thus, while the modeling efforts have indicated that cracks may form from relatively small pores (a single pore $20 \mu \mathrm{m}$ in size or two 10$\mu \mathrm{m}$ pores) and the in situ experiments confirmed the existence of cracks from these small pores, these cracks did not experience significant growth, compared with surface-connected cracks. Hence, the surface condition (especially in terms of surface roughness) can be potentially more damaging than the presence of small pores. Hot isostatic pressing is often used to reduce the degree of porosity in AM materials, ${ }^{12}$ but from the present study, we can conclude that HIPing will only be beneficial to the fatigue performance in cases of a nearly pristine surface (in other words, for AM materials not possessing as-built surface finishes).

\section{CONCLUSION}

An integrated computational materials engineering framework was adopted to identify the critical (minimum) pore size that will debit the overall fatigue life of the material. Through crystal plasticity modeling, a single $20-\mu \mathrm{m}$-sized pore or two 10 $\mu \mathrm{m}$ pores with centers spaced $15 \mu \mathrm{m}$ apart will develop stress concentrations in the vicinity of the pore that are higher than the stresses elsewhere in the microstructure, thus being used to determine the critical pore size for this material, which contained an average grain size of $50 \mu \mathrm{m}$ (including twins). In comparison, a single $10-\mu$ m pore did not generate such stress concentration. In situ highenergy x-ray characterization was used on a specimen that was subjected to cyclic loading. Within 
this specimen, 18 cracks were observed (10 cracks that originated from a pore and were present during the first tomography scan, five cracks that initiated from pores during cyclic loading, and three cracks that formed at the free surface). The grain-averaged stress fields in most grains that initiated a crack were quantified to be significantly higher than the average stress state in the material, although this analysis does not capture stress gradients near pores and may not capture small grains in the vicinity of the pores. The cracks originating from pores experienced negligible propagation, while the three surface cracks exhibited significant propagation with one surface-connected crack growing to over a quarter of the specimen width and therefore being deemed as the dominant crack. The stress in the grains that originated a crack, whether at the free surface or in the vicinity of a pore, had similar values. Additionally, the geometric correction factor on the stress intensity for a surface-connected crack is $12 \%$ higher than in the bulk of the sample. Thus, it would be expected that the surface cracks would be more prone to propagate than the crack in the bulk of the material, thus the surface condition (and associated surface roughness) may be more damaging than small pores. From the over 10,000 pores characterized in the ROI, only five were greater than $20 \mu \mathrm{m}$ in size; for the remaining pores, crack initiation in the bulk material is improbable (as surface cracking and subsequent propagation are more likely) in spite of the high density of pores.

\section{ACKNOWLEDGEMENTS}

Support for this work was provided by DARPA under Contract N66001-14-1-4041 with program managers M. Maher and J. Vanderbrande. The IN718 specimens were manufactured by R. Martukanitz and K. Meinert at Penn State University's Center for Innovative Materials Processing through Direct Digital Deposition (CIMP-3D). The authors would like to thank Dr. D. Naragani for assistance with data collection during the in situ experiments and helpful discussions regarding data reconstruction, A. Mallory for fractography analysis, Dr. T. Book for preliminary material characterization, J. Rotella for assistance during the in situ experiments, and Dr. H. Sharma of the Argonne National Laboratory for help with ff-HEDM data reconstruction. Use of the Advanced Photon Source was supported by the US Department of Energy, Office of Science, Office of Basic Energy Sciences, under Contract No. DE-AC02-06CH11357.

\section{REFERENCES}

1. W.E. Frazier, J. Mater. Eng. 23, 1917 (2014).

2. M. Gorelik, Int. J. Fatigue 94, 168 (2017).

3. J.-P. Choi, G.-H. Shin, S. Yang, D.-Y. Yang, J.-S. Lee, M. Brochu, and J.-H. Yu, Powder Technol. 310, 60 (2017).

4. G. Kasperovich, J. Haubrich, J. Gussone, and G. Requena, Mater. Des. 105, 160 (2016).

5. P. Edwards and M. Ramulu, Mater. Sci. Eng. A 598, 327 (2014).
6. S. Tammas-Williams, P.J. Withers, I. Todd, and P.B. Prangnell, Sci. Rep. 7, 7308 (2017).

7. T. Mishurova, K. Artzt, J. Haubrich, G. Requena, and G. Bruno, Add. Manuf. 25, 325 (2019).

8. S. Tammas-Williams, H. Zhao, F. Léonard, F. Derguti, I. Todd, and P.B. Prangnell, Mater. Charact. 102, 47 (2015).

9. J. Stef, A. Poulon-Quintin, A. Redjaimia, J. Ghanbaja, O. Ferry, M. De Sousa, and M. Gouné, Mater. Des. 156, 480 (2018).

10. G. Kasperovich and J. Hausmann, J. Mater. Process. Technol. 220, 202 (2015).

11. H. Gong, K. Rafi, N. V. Karthik, T. L. Starr and B. Stucker, in Defect Morphology in Ti-6Al-4 V Parts Fabricated by Selective Laser Melting and Electron Beam Melting, Solid Freeform Fabrication Symposium (2012).

12. R. Cunningham, A. Nicolas, J. Madsen, E. Fodran, E. Anagnostou, M.D. Sangid, and A.D. Rollett, J. Mater. Res. 5, 516 (2017).

13. M.D. Sangid, T.A. Book, D. Naragani, J. Rotella, P. Ravi, A. Finch, P. Kenesei, J.-S. Park, H. Sharma, J. Almer, and X. Xiao, Add. Manuf. 22, 479 (2018).

14. S. Leuders, M. Thöne, A. Riemer, T. Niendorf, T. Tröster, H.A. Richard, and H.J. Maier, Int. J. Fatigue 48, 300 (2013).

15. L. Sheridan, O.E. Scott-Emuakpor, T. George, and J.E. Gockel, Mater. Sci. Eng. A 727, 170 (2018).

16. X. Shui, K. Yamanaka, M. Mori, Y. Nagata, K. Kurita, and A. Chiba, Mater. Sci. Eng. A 680, 239 (2017).

17. M. Zhang, C.-N. Sun, X. Zhang, J. Wei, D. Hardacre, and H. Li, Mater. Des. 145, 42 (2018).

18. R. Biswal, A.K. Syed, and X. Zhang, Add. Manuf. 23, 433 (2018).

19. X. Zhou, D. Wang, X. Liu, D. Zhang, S. Qu, J. Ma, G. London, Z. Shen, and W. Liu, Acta Mater. 98, 1 (2015).

20. H. Gong, K. Rafi, T. L. Starr and B. Stucker, in Effect of Defects on Fatigue Tests of As-Built Ti-6Al-4 V Parts Fabricated by Selective Laser Melting, Solid Freeform Fabrication Symposium (2012).

21. Q.G. Wang, D. Apelian, and D.A. Lados, J Light Metals 1, 73 (2001).

22. H.T. Pang and P.A.S. Reed, Int. J. Fatigue 25, 1089 (2003).

23. Y. Murakami and M. Endo, Int. J. Fatigue 16, 163 (1994).

24. C. Garb, M. Leitner, and F. Grün, Eng. Fract. Mech. 185, 61 (2017).

25. B.M. Schönbauer and H. Mayer, Int. J. Fatigue 127, 362 (2019).

26. H. Kitagawa, in Proc. of 2nd ICM, Cleveland, pp. 627-631 (1976).

27. M. Seifi, A. Salem, J. Beuth, O. Harrysson, and J.J. Lewandowski, JOM 68, 747 (2016).

28. M. Seifi, M. Gorelik, J. Waller, N. Hrabe, N. Shamsaei, S. Daniewicz, and J.J. Lewandowski, JOM 69, 439 (2017).

29. T.M. Pollock and J. Allison, Integrated computational materials engineering: a transformational discipline for improved competitiveness and national security (Washington, DC: The National Academies Press, 2008).

30. National Science and Technology Council, in Materials Genome Initiative for Global Competitiveness (2011).

31. National Academies of Sciences, Engineering and Medicine, in Predictive Theoretical and Computational Approaches for Additive Manufacturing: Proceedings of a Workshop (National Academies Press, 2016).

32. F. Roters, P. Eisenlohr, L. Hantcherli, D.D. Tjahjanto, T.R. Bieler, and D. Raabe, Acta Mater. 58, 1152 (2010).

33. C.C. Battaile, J.M. Emery, L.N. Brewer, and B.L. Boyce, Philos. Mag. 95, 1069 (2015).

34. V. Prithivirajan and M.D. Sangid, J. Mater. Des. 150, 139 (2018).

35. J.C. Schuren, P.A. Shade, J.V. Bernier, S.F. Li, B. Blank, J. Lind, P. Kenesei, U. Lienert, R.M. Suter, and T.J. Turner, Curr. Opin. Solid State Mater. Sci. 19, 235 (2015).

36. S. Tammas-Williams, P.J. Withers, I. Todd, and P.B. Prangnell, Metall. Mater. Trans. A 47, 1939 (2016).

37. T.J. Marrow, J.Y. Buffiere, P.J. Withers, G. Johnson, and D. Engelberg, Int. J. Fatigue 26, 717 (2004). 
38. E. Maire and P.J. Withers, Int. Mater. Rev. 59, 1 (2014).

39. P.J. Withers and M. Preuss, Annu. Rev. Mater. Res. 42, 81 (2012).

40. L. Margulies, T. Lorentzen, H.F. Poulsen, and T. Leffers, Acta Mater. 50, 1771 (2002).

41. J. Oddershede, S. Schmidt, H.F. Poulsen, H.O. Sorensen, J. Wright, and W. Reimers, J. Appl. Crystall. 43, 539 (2010).

42. J.V. Bernier, N.R. Barton, U. Lienert, and M.P. Miller, J. Strain Anal. Eng. Des. 46, 527 (2011).

43. Y.S.J. Yoo, T.A. Book, M.D. Sangid, and J. Kacher, Mater. Sci. Eng. A 724, 444 (2018).

44. J.J. Williams, K.E. Yazzie, E. Padilla, N. Chawla, X. Xiao, and F. De Carlo, Int. J. Fatigue 57, 79 (2013).

45. S.T. Carter, J. Rotella, R.F. Agyei, X. Xiao, and M.D. Sangid, Int. J. Fatigue 116, 490 (2018).

46. C.A. Schneider, W.S. Rasband, and K.W. Eliceiri, Nat. Methods 9, 671 (2012).

47. P.A. Shade, D.B. Menasche, J.V. Bernier, P. Kenesei, J.-S. Park, R.M. Suter, J.C. Schuren, and T.J. Turner, J. Appl. Crystall. 49, 700 (2016).

48. P.A. Shade, B. Blank, J.C. Schuren, T.J. Turner, P. Kenesei, K. Goetze, R.M. Suter, J.V. Bernier, S.F. Li, and J. Lind, Rev. Sci. Instrum. 86, 093902 (2015).

49. H. Sharma, R.M. Huizenga, and S.E. Offerman, J. Appl. Crystall. 45, 693 (2012).

50. H. Sharma, R.M. Huizenga, and S.E. Offerman, J. Appl. Crystall. 45, 705 (2012).

51. H.F. Poulsen, Three-dimensional X-ray diffraction microscopy: mapping polycrystals and their dynamics (Berlin: Springer, 2004).
52. A. Khounsary, P. Kenesei, J. Collins, G. Navrotski, J. Nudell, in J. Phys. Conf. Ser., p. 212015. (IOP Publishing, 2013).

53. Z. Konrad, User's Guide - Avizo (2017).

54. M.A. Groeber and M.A. Jackson, Integr. Mater. Manuf. Innov. 3, 5 (2014).

55. E.H. Lee and D.T. Liu, J. Appl. Phys. 38, 19 (1967).

56. J.W. Hutchinson, Proc. R. Soc. Lond. A 348, 101 (1976).

57. P. J. Armstrong, C. Frederick (1966). A mathematical representation of the multiaxial Bauschinger effect. Central Electricity Generating Board and Berkeley Nuclear Laboratories.

58. R. Bandyopadhyay, V. Prithivirajan, and M.D. Sangid, JOM 71, 2612 (2019).

59. S.C. Wu, T.Q. Xiao, and P.J. Withers, J. Eng. Fract. Mech. 182, 127 (2017)

60. P.J. Withers, Philos. Trans. R. Soc. A Math. Phys. Eng. Sci. 373, 20130157 (2015).

61. B. Yu, R.S. Bradley, C. Soutis, and P.J. Withers, J. Philos. Trans. R. Soc. Math. Phys. Eng. Sci. 374, 20160037 (2016).

62. A. Rovinelli, M.D. Sangid, H. Proudhon, and W. Ludwig, NPJ Comput. Mater. 4, 35 (2018).

63. T.L. Anderson, Fracture Mechanics: Fundamentals and Applications (Boca Raton: CRC Press, 2005).

Publisher's Note Springer Nature remains neutral with regard to jurisdictional claims in published maps and institutional affiliations. 